Farum

Sociológico

\section{Forum Sociológico}

Série II

$21 \mid 2011$

Transformação urbana

\title{
Associações científicas portuguesas: mapeamento e caracterização
}

Ana Delicado, Luís Junqueira, Raquel Rego, Cristina Conceição e Inês Pereira

\section{(2) OpenEdition}

12 Journals

Edição electrónica

URL: https://journals.openedition.org/sociologico/459

DOI: $10.4000 /$ sociologico.459

ISSN: $2182-7427$

Editora

CICS.NOVA - Centro Interdisciplinar de Ciências Sociais da Universidade Nova de Lisboa

Edição impressa

Data de publição: 1 dezembro 2011

Paginação: 97-107

ISSN: 0872-8380

\section{Refêrencia eletrónica}

Ana Delicado, Luís Junqueira, Raquel Rego, Cristina Conceição e Inês Pereira, «Associações científicas portuguesas: mapeamento e caracterização», Forum Sociológico [Online], 21 | 2011, posto online no dia 05 setembro 2012, consultado o 29 março 2022. URL: http://journals.openedition.org/sociologico/ 459 ; DOI: https://doi.org/10.4000/sociologico.459

Este documento foi criado de forma automática no dia 29 março 2022.

(C) CICS.NOVA 


\title{
Associações científicas portuguesas: mapeamento e caracterização
}

\author{
Ana Delicado, Luís Junqueira, Raquel Rego, Cristina Conceição e Inês \\ Pereira
}

\section{Introdução}

1 As associações científicas são um dos elementos dos sistemas científicos menos conhecidos e debatidos no âmbito da Sociologia da Ciência. Perante o crescente relevo social da ciência contemporânea, o seu papel carece de ser analisado. Em Portugal, o avultado investimento em ciência nas últimas décadas tem-se traduzido num desenvolvimento das instituições de investigação e ensino, da comunidade e da produção científica, que terá também reflexos sobre este tipo de organização.

2 Este artigo, inserido num projecto de investigação em curso que tem por objectivo compreender o papel das associações científicas na ciência contemporânea em Portugal $^{1}$, procura fazer uma primeira caracterização geral destas entidades. Após um breve enquadramento teórico, são apresentados dados relativos à distribuição temporal, espacial e disciplinar das associações científicas. Procura-se depois aferir não só a ligação entre as associações científicas e o sistema científico nacional, mas também com outras esferas da sociedade, através das actividades que desenvolvem, da base de associados e das fontes de financiamento com que se sustentam.

\section{Enquadramento}

3 As sociedades e associações científicas são um tema genericamente ignorado dentro dos estudos de ciência e da sociologia da ciência em particular. Se o seu papel histórico no dealbar da ciência moderna é amplamente referido (Merton, 1938; Shapin, 1999: 140-143; Golinski, 1999) e abundam as monografias sobre as instituições mais relevantes, como a Royal Society (Lynch, 2001; Bryson, 2010), pouca atenção é dada às suas funções na ciência contemporânea. Apesar de as teorizações em torno do Modo 2 
de produção de conhecimento (Gibbons et al., 1997) pressuporem a diversificação das instituições envolvidas na ciência, as associações científicas praticamente não são referidas.

Há, no entanto, alguns trabalhos sobre associações científicas contemporâneas. Schofer (1999, 2003) tem estudado o crescimento das organizações não governamentais internacionais científicas, sintomático da globalização da ciência mas também da procura de respostas científicas a problemas sociais. Focando-se no caso de um sistema científico em particular, o estudo de Schimank (1988) sobre as associações científicas alemãs procura caracterizar as suas funções e actividades. Num âmbito mais disciplinar, Moreau et al. (2004) aplicaram um inquérito às sociedades médicas francesas com o objectivo de chegar a uma definição consensual e construir uma tipologia. Sobre associações específicas encontra-se, por exemplo, a monografia de Rilling (1986) sobre a Sociedade Alemã de Química, que demonstra a sua função importante no estabelecimento de laços entre o sistema social da ciência e os ambientes sociais externos (como canal de controlo social).

Existem ainda estudos dispersos (e produzidos sobretudo por investigadores das áreas disciplinares respectivas, mais que por cientistas sociais) sobre o papel das associações em áreas diversas. Vários autores têm-se debruçado sobre o exercício da regulação ética por parte das associações científicas, analisando os seus códigos de conduta (Bird, 1998; Bullock e Panicker, 2003) ou a promoção da integridade na publicação científica (Caelleigh, 2003). O papel das associações científicas com editoras de revistas tem suscitado também outro tipo de análise, centrado, por exemplo, nos seus custos (Shad, 1997) ou na oportunidade ou ameaça que representa o acesso livre (Velterop, 2003). Um terceiro grupo de trabalhos diz respeito à participação das associações na definição de políticas públicas, em áreas como a saúde (Vesikari, 2008) ou os recursos naturais (Scott et al., 2008).

6 Em Portugal, a temática das associações está razoavelmente estudada, com trabalhos publicados, por exemplo, sobre associações profissionais (Freire, 2004), ONG de ambiente (Nave e Fonseca 2000), ou associações de desenvolvimento local (Melo, 2011)2. Porém, no que diz respeito às associações científicas, pouco existe para além de estudos históricos sobre algumas sociedades científicas, como a Academia das Ciências ou a Sociedade de Geografia de Lisboa, ou sobre tipos específicos de associação (Matos, 1996) ou ainda referências esparsas em análises sobre a política científica portuguesa (Gonçalves, 1996: 53) e sobre actividades de cultura científica (Costa et al., 2005: 45, 82-83).

\section{Metodologia}

7 Os dados apresentados neste artigo sustentam-se em três diligências metodológicas: um recenseamento das associações científicas, uma análise dos estatutos das associações e um inquérito por questionário aplicado a uma amostra das mesmas.

$8 \mathrm{Na}$ ausência de uma definição estabilizada de associação científica na literatura científica ou no regime legal português (ao contrário do que sucede em outras áreas mais enquadradas institucionalmente em Portugal, como as IPSS, as associações de defesa do ambiente, de jovens, etc.) ou ainda de um registo centralizado destas instituições, o recenseamento de associações partiu da combinação de uma pluralidade 
de fontes disponíveis ${ }^{3}$. Foram definidos pela equipa quatro critérios primordiais de avaliação das associações: tem designação de associação científica; tem fins científicos (explícitos nos estatutos); desenvolve actividades científicas; os cientistas são um tipo significativo de membros (em número ou nos cargos de direcção).

Com recurso a documentação e à internet, procurou-se reunir informação sobre as associações recenseadas de modo a sustentar a aplicação destes critérios. Foi assim constituída uma base de dados onde consta o nome da associação, contactos, webpage, data de fundação, área científica, objectivos e actividades. Esta base de dados contém actualmente 443 registos. No entanto, é importante referir que este recenseamento se baseia numa concepção alargada de associação científica, que inclui muitos casos de associações cuja área de actividade principal é outra (defesa do ambiente, promoção da saúde, protecção do património cultural, defesa de interesses profissionais, etc.) mas que estão de alguma forma ligadas ao meio científico. A par deste esforço de recenseamento, foram também recolhidos e sujeitos a uma análise de conteúdo sistemática os estatutos de 262 associações científicas.

Foi por fim aplicado um inquérito por questionário às associações científicas com o objectivo de obter uma caracterização mais completa destas organizações. $O$ inquérito decorreu entre Outubro de 2010 e Maio de 2011, tendo sido aplicado online às 337 associações para as quais foi identificado um endereço de email válido ${ }^{4}$. Foram recebidas 107 respostas, correspondentes a uma taxa de $31,7 \%$.

Figura 1 Total acumulado do número de associações científicas e cronologia de eventos políticoinstitucionais, 1901-2011

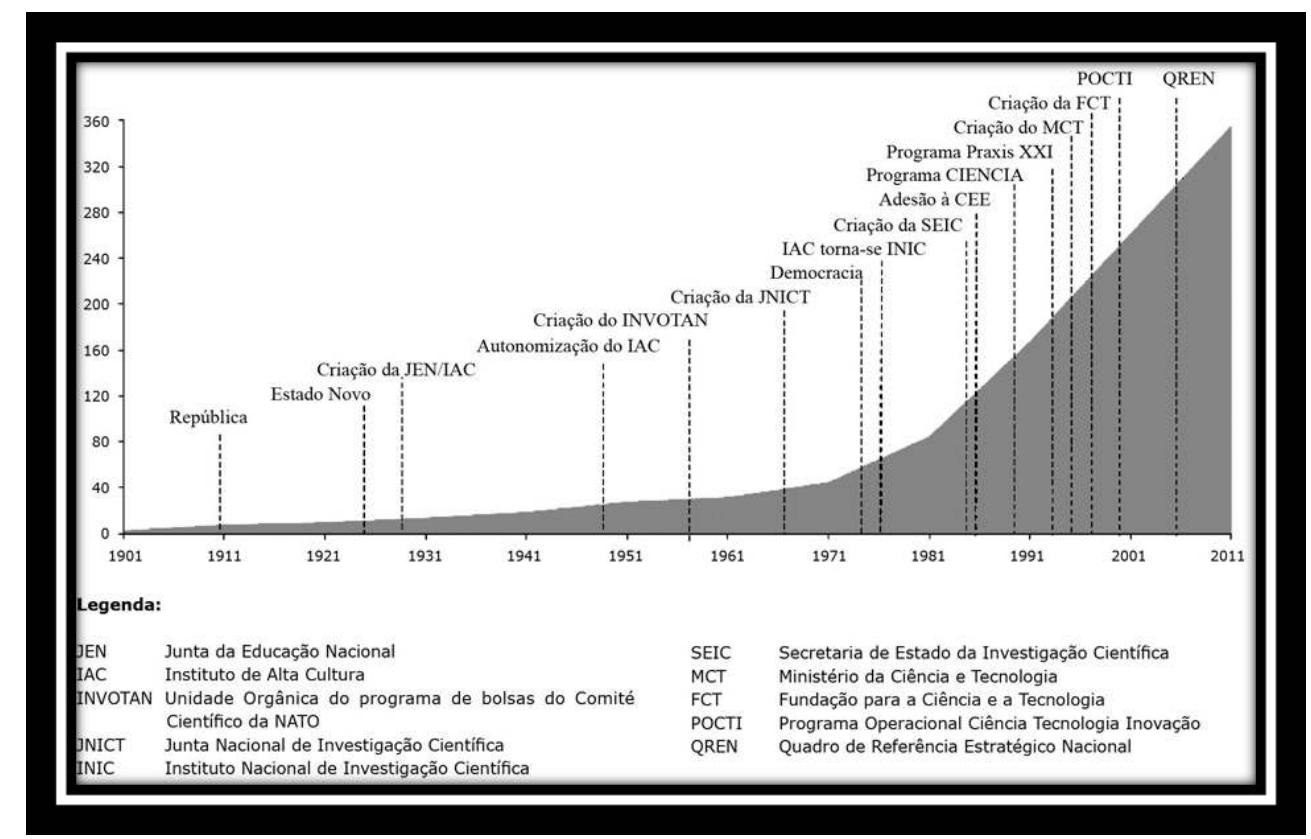

FONTE: Recenseamento às associações científicas nacionais (2011)

\section{Mapeamento do universo das associações científicas}

11 Um primeiro dado relevante para caracterizar as associações científicas portuguesas diz respeito ao momento de criação das associações ${ }^{6}$. Pode-se constatar que o 
crescimento das associações científicas acompanha o desenvolvimento do sistema científico português, tanto em termos de estruturação institucional (Figura 1) como de investimento e recursos humanos (Figura 2). Assim, verifica-se que o número de associações científicas era quase irrisório até à Primeira República ${ }^{7}$, cresceu muito lentamente até meados do século ${ }^{8}$ e acelerou um pouco com o início da política científica nos anos 60, marcada pela criação da JNICT (Ruivo, 1998: 216), apesar das limitações ao associativismo e da secundarização da ciência durante o Estado Novo (Gonçalves, 2001: 177). É no entanto a partir dos anos 80 que se dá o verdadeiro arranque no desenvolvimento científico português, com a entrada da ciência na orgânica dos governos (primeiro como Secretaria de Estado, depois como Ministério) e a criação de programas estáveis de financiamento (CIENCIA, PRAXIS XXI, POCTI, QREN) (Gonçalves, 1996), com o correspondente crescimento dos recursos financeiros e humanos em investigação. Este desenvolvimento é acompanhado pela fundação de um número crescente de associações científicas e de uma organização agregadora, a Federação Portuguesa das Associações e Sociedades Científicas (FEPASC), criada no início dos anos 90 (Gonçalves, 1996) e que está hoje praticamente inactiva.

Figura 2 Total acumulado de associações científicas (eixo da esquerda), despesa em I\&D em percentagem do PIB e investigadores em I\&D por mil activos (eixo da direita), 1980-2011

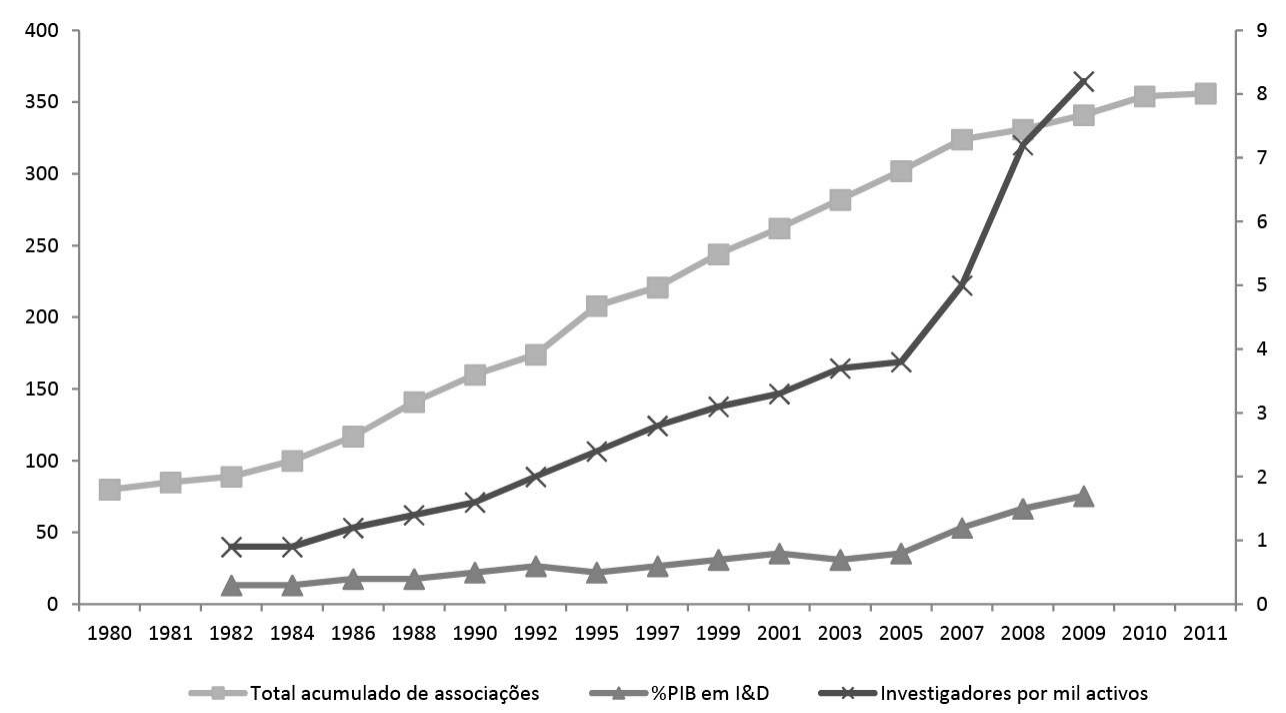

FONTE: GPEARI, Inquérito ao Potencial Científico e Tecnológico Nacional e recenseamento de associações científicas

12 Quanto à distribuição geográfica das associações recenseadas (Figura 3), verifica-se uma forte concentração de associações científicas em Lisboa e concelhos da respectiva área metropolitana (56\%), seguida do Porto (14\%), Coimbra (8\%) e ainda de Braga, Setúbal, Aveiro e Algarve (4\%). Tal explica-se não só pela contracção regional do sistema científico português ${ }^{9}$, mas também pela localização das principais universidades portuguesas. De facto, quase um terço das associações científicas indica como sede as instalações de estabelecimentos de ensino superior, laboratórios do Estado ou centros de investigação. Tal dever-se-á não só à imbricação das associações no campo científico, mas também ao controlo de custos de funcionamento das associações.

Considerando a área disciplinar das associações científicas (Figura 4), predominam as ciências médicas e da saúde ( $35 \%$ das associações), seguidas das ciências naturais, 
humanidades, ciências sociais e ciências da engenharia. Esta distribuição não tem qualquer correspondência linear com a estruturação do campo científico português, como pode ser demonstrado através dos resultados mais recentes do Inquérito ao Potencial Científico e Tecnológico Nacional (GPEARI, 2011): a área que efectua maior despesa e congrega um maior volume de recursos humanos é a das ciências da engenharia, seguida da das ciências exactas.

o que explica a predominância das ciências médicas e da saúde no campo das associações é o facto de a sua divisão disciplinar interna se reflectir de forma mais marcada na constituição de associações científicas: enquanto nas ciências exactas uma única associação praticamente representa toda uma área disciplinar ${ }^{10}$ (por exemplo, a Sociedade Portuguesa de Matemática, a Sociedade Portuguesa de Física ou a Sociedade Portuguesa de Astronomia), nas ciências da saúde existem mais de uma centena de associações divididas por especialidades e subespecialidades médicas ${ }^{11}$, muitas originadas a partir da Sociedade de Ciências Médicas de Lisboa. Tal poderá estar associado ao trajecto de especialização da medicina (Weisz, 2003), mas uma dispersão de associações semelhante sucede noutras disciplinas, como a biologia, a psicologia ou a filosofia. Para Schimank (1988), a criação de uma associação é indicador da institucionalização social da disciplina; muitas associações começam como núcleos dentro de associações mais antigas, que depois se autonomizam, quando o núcleo atinge massa crítica suficiente. Assim, o crescimento das associações sucederá eventualmente em resposta à crescente especialização disciplinar da ciência (Caraça, 2001; Barke, 2003; Schofer, 2003), mas já as razões para a concentração em algumas áreas e para a dispersão noutras terão de ser aferidas noutras fases do projecto.

Figura 3 Distribuição regional (NUTS III) das associações científicas

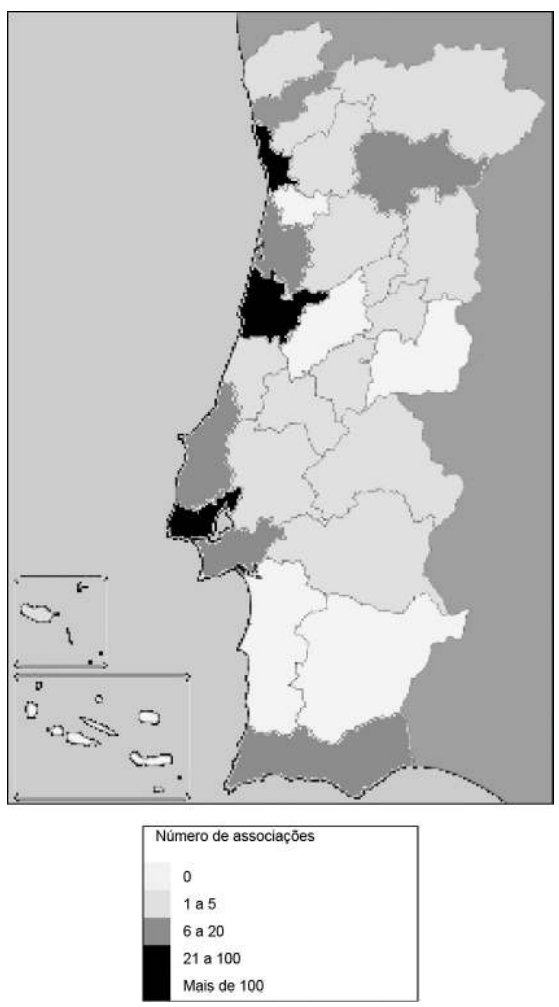

FONTE: Recenseamento às associações científicas nacionais (2011) 


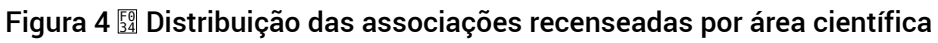

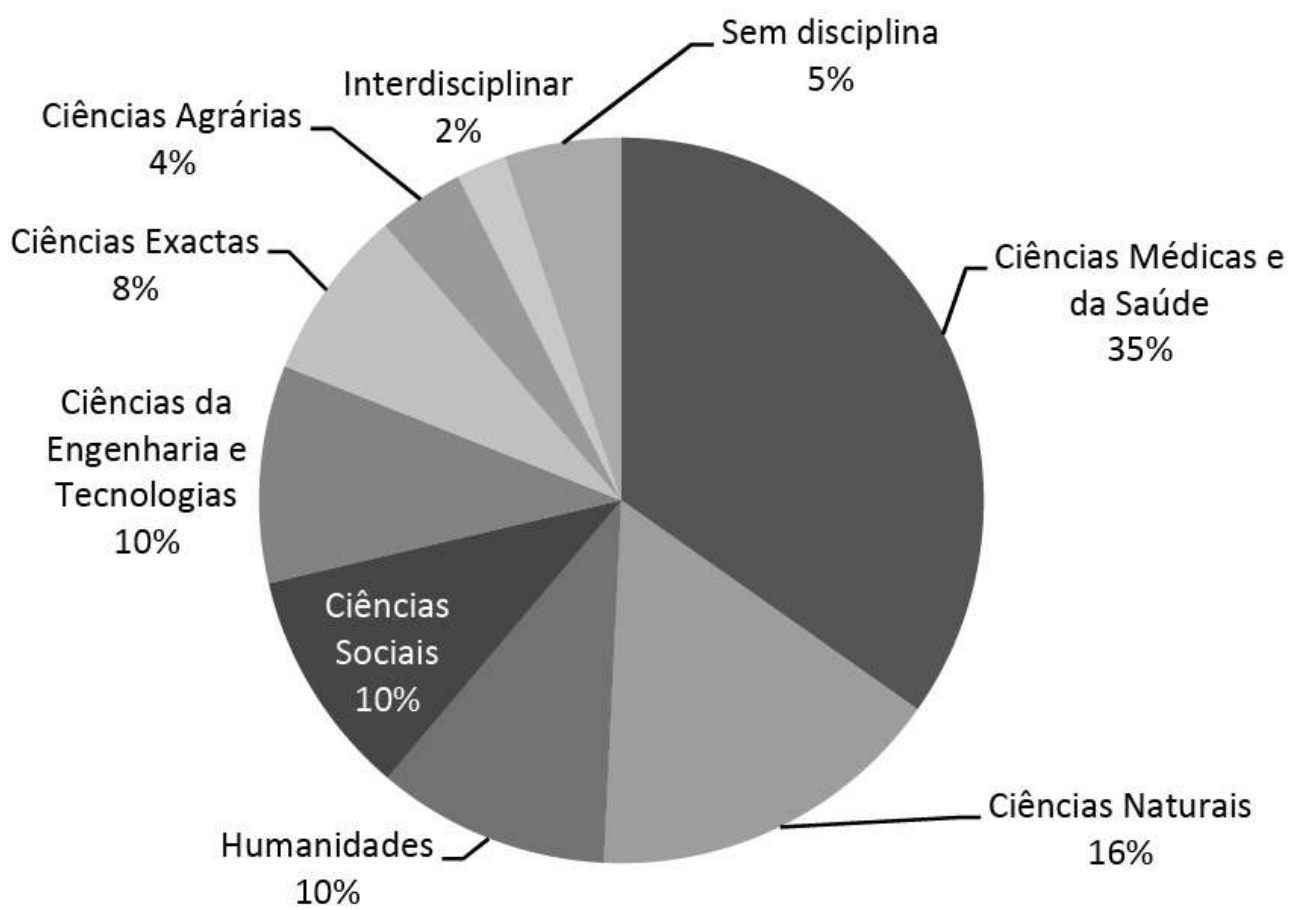

$N=443$; FONTE: Recenseamento às associações científicas nacionais (2011)

\section{Composição interna das associações científicas}

O inquérito aplicado às associações científicas permite analisar em maior pormenor as características das associações científicas portuguesas, nomeadamente a sua composição interna.

Uma primeira constatação possível é a reduzida dimensão média das associações científicas portuguesas, inferior, por exemplo, às associações profissionais (Freire, 2004: 14). Perto de $20 \%$ das associações inquiridas tem menos de uma centena de membros, $22 \%$ tem entre 100 e 250 membros e $40 \%$ entre 250 e mil membros. Apenas $18 \%$ das associações reúnem mais de mil sócios.

Mas é na distribuição por categorias de associados (Figura 5) que se pode apreciar a forte aproximação ao campo científico: praticamente todas as associações contam com investigadores (95\%) ou outros profissionais científicos e técnicos (84\%) entre os seus associados e em cerca de metade dos casos estes grupos constituem mais de $25 \%$ do total de associados. É de notar que também nos órgãos sociais das associações os investigadores têm uma presença importante, fazendo parte dos órgãos de $96 \%$ das associações inquiridas. Numa proporção relevante de associações (42\%) os investigadores constituem a maioria ou a totalidade dos membros dos órgãos sociais. 
Figura 5 Distribuição das associações por peso dos tipos de associados (\%)

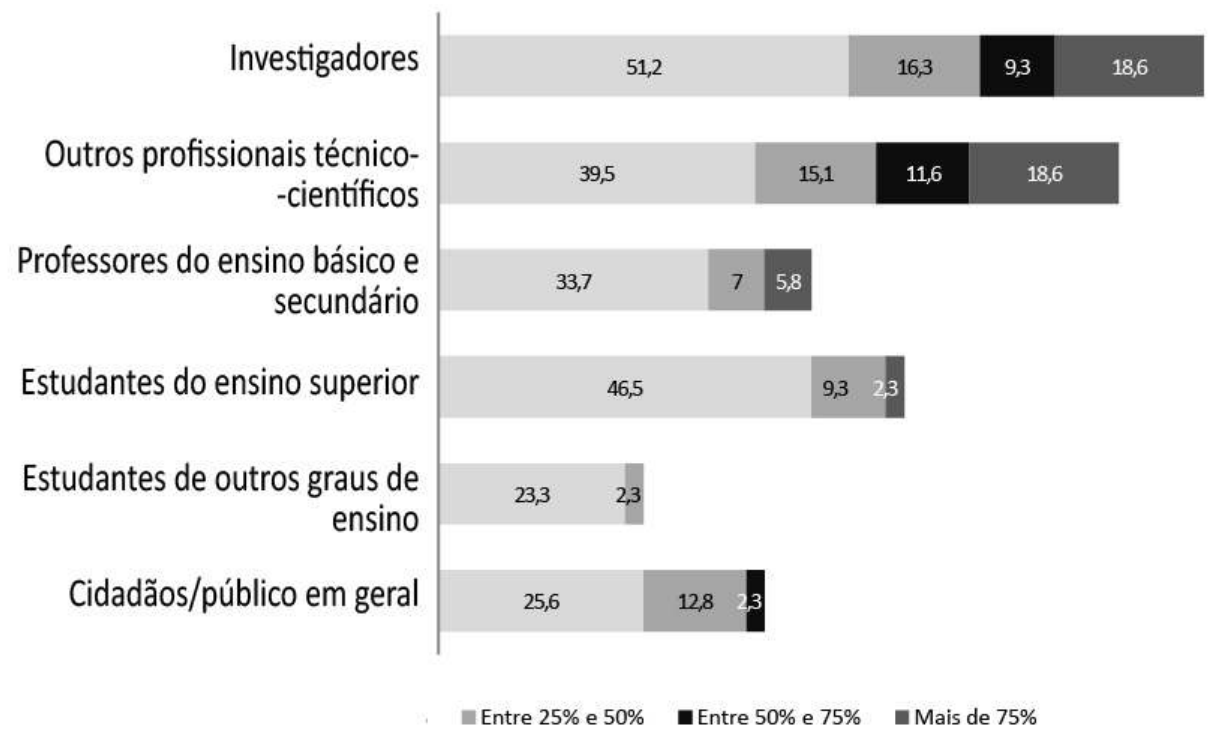

N = 86; FONTE: Inquérito às associações científicas portuguesas (2011) universitários estão presentes em $57 \%$ das associações) e responsáveis pela formação pré-graduada (professores do ensino secundário em 45\% das associações).

Já a ligação à sociedade é mais ténue: mais de metade destas associações (59\%) não admite como associados cidadãos ou público em geral.

De facto, a análise dos estatutos das associações revelou que, entre as que referem os sócios nos estatutos (221 casos, $84 \%$ dos estatutos analisados), a maioria (83\%) impõe limitações à admissão de sócios efectivos, a categoria pela qual são geralmente designados os sócios de pleno direito (com direito a participar nos processos de decisão e a pertencer aos órgãos sociais). Para além de critérios etários ou de nacionalidade, entre os requisitos mais frequentes podemos encontrar:

- a actividade ou experiência profissional numa determinada área (em 53\% das associações) Ex.: "Podem ser membros singulares os cientistas, técnicos, estudantes e outras pessoas cuja actividade se insira no âmbito de Epidemiologia" (Estatutos da Associação Portuguesa de Epidemiologia);

- o grau académico numa disciplina (24\%) - Ex.: "Podem ser admitidos como associados efectivos da APEZ os licenciados em cursos de Engenharia Zootécnica ou licenciaturas similares acreditados e/ou reconhecidos pela Ordem dos Engenheiros" (Estatutos da Associação Portuguesa de Engenharia Zootécnica);

- uma habilitação profissional reconhecida (10\%) - Ex.: "Podem ser Sócios Titulares todos os médicos inscritos no colégio da especialidade de ortopedia da Ordem dos Médicos que reúnam as condições e estejam em plena posse dos seus direitos civis e profissionais" (Estatutos da Sociedade Portuguesa de Ortopedia e Traumatologia);

- actividades de investigação científica (2\%), incluindo mesmo em alguns casos a exigência de publicação - Ex.: "São associados efectivos os autores de pelo menos dois artigos científicos de Farmacologia, Farmacologia Clínica, Toxicologia, ou ciências afins, publicados em revistas científicas arbitradas e indexadas no Science Citation Index, e que tenham 
apresentado pelo menos uma comunicação científica oral nas reuniões da SPF" (Estatutos da Sociedade Portuguesa de Farmacologia).

21 Ainda é importante notar a existência de algumas associações que apontam mais que um critério de restrição para o estatuto de sócio efectivo (20\%), sendo que entre estas é mais frequente a combinação de critérios relacionados de actividade/experiência profissional com critérios de habilitações académicas (8\%). Algumas associações exigem no processo de candidatura a apresentação de $\mathrm{CV}$, certificados de habilitações ou mesmo a prestação de provas.

\section{Recursos financeiros das associações científicas}

A reduzida dimensão das associações científicas pode também ser aferida pelo seu volume anual de despesa. De acordo com os dados recolhidos através do inquérito por questionário, perto de um terço das associações inquiridas afirma ter tido um volume de despesas inferior a 5 mil euros durante 2009 e um quarto entre 5 e 20 mil euros. Apenas cerca de $20 \%$ das associações declara um volume de despesas superior a $100 \mathrm{mil}$ euros.

Como seria de esperar, as duas medidas de dimensão das associações estão associadas: $52 \%$ das associações com uma despesa anual inferior a 5 mil euros têm menos de 200 sócios, $65 \%$ das associações com uma despesa superior a 100 mil euros têm mais de 500 sócios.

Figura 6 Distribuição das fontes de financiamento das associações (\%)

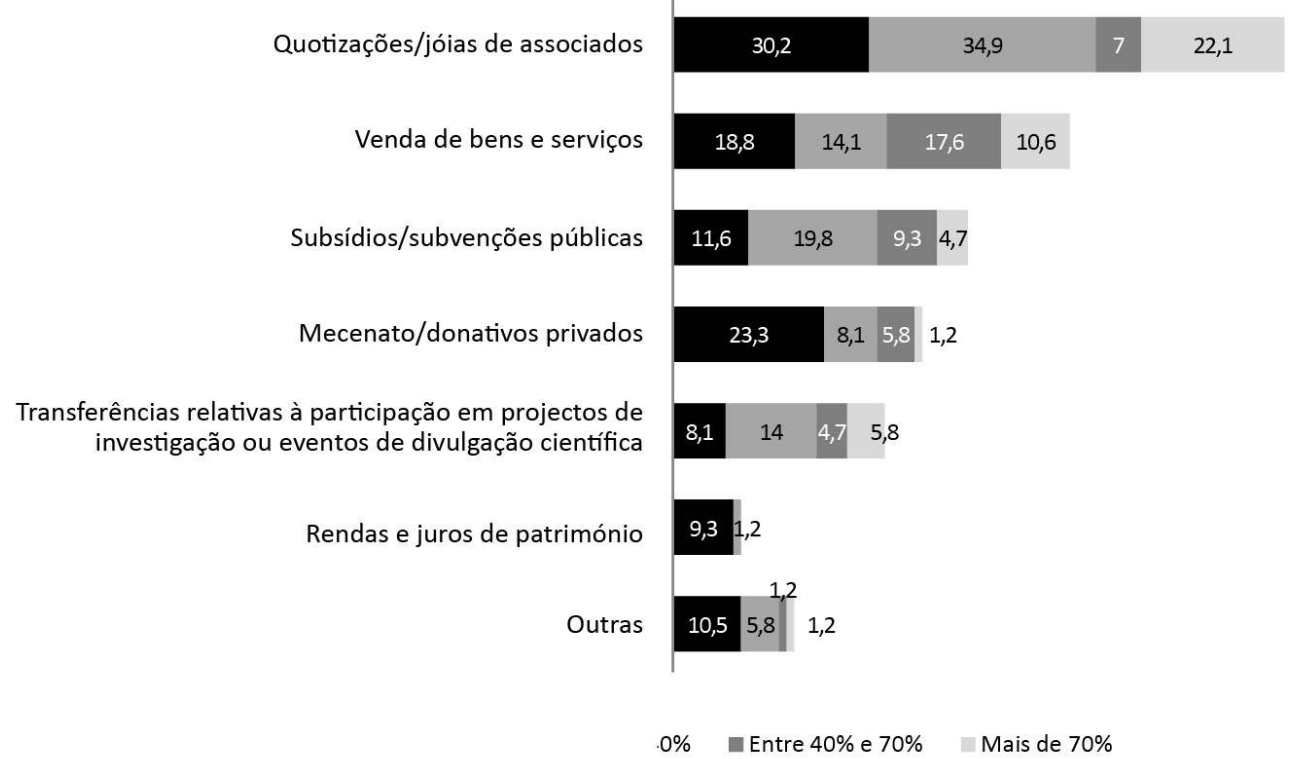

N = 86; FONTE: Inquérito às associações científicas portuguesas (2011)

Mas é através das fontes de financiamento das associações científicas que se pode avaliar a sua base de apoio social (Figura 6). É importante notar que as associações científicas dependem sobretudo de rendimentos próprios para assegurar as suas actividades: entre as receitas das associações destacam-se as quotizações e jóias de associados, num primeiro plano (22\% das associações afirma depender em mais de $70 \%$ 
deste tipo de rendimentos), a venda de bens e serviços de carácter científico, em segundo plano, e a remuneração por participação em projectos e eventos, num terceiro plano. Mais de metade das associações científicas não recebe qualquer apoio financeiro público, o que contrasta com organizações do terceiro sector noutras áreas de actividade, como a solidariedade social (vide, por exemplo, Delicado et al., 2002) ou o ambiente (Nave e Fonseca, 2000), onde o financiamento estatal é predominante. Os donativos privados também são minoritários.

\section{Actividades das associações científicas}

Por fim, um outro elemento essencial para compreender o papel das associações científicas diz respeito às actividades desenvolvidas. Os poucos estudos existentes sobre associações científicas contemporâneas destacam o carácter plurifuncional das associações científicas, cujas actividades enquadram não só as funções de desenvolvimento da disciplina (comunicação e reprodução do conhecimento científico) mas também funções de natureza profissional (representação de interesses da disciplina e seus profissionais, apoio na procura de emprego) e de ligação com a sociedade (aconselhamento de políticas públicas e divulgação científica). No que respeita às associações científicas na Alemanha, Schimank (1988) identifica quatro funções principais: a função comunicacional (difusão de resultados interna à disciplina, entre profissionais), a função profissional (aconselhamento e apoio a estudantes, cursos de formação profissional, representação dos interesses junto da comunidade científica e da sociedade), a função de transferência (promover encontro entre cientistas e utilizadores dos resultados) e a função de promoção (promover projectos de investigação, contactos com centros de I\&D e instituições políticas, aconselhamento em matéria de política científica, representação em decisões políticas e administrativas). Moreau et al. (2004) reconheceram cinco objectivos principais das sociedades científicas médicas francesas: desenvolvimento científico (investigar, promover, favorecer o estudo, desenvolver, difundir, dar a conhecer, coordenar, fazer progredir, publicação, informação, apresentação de trabalhos), comunicação, formação (ensino), defesa da disciplina ou profissão (representação junto das instituições), divulgação de novidades da disciplina (sobre avaliação e prevenção, qualidade, ética, educação do paciente, acreditação). Rilling (1986) salienta a plurifuncionalidade da Sociedade Alemã de Química, que opera simultaneamente como associação profissional (agência de emprego para químicos, estabelecimento de requisitos de competências profissionais, demarcação de outras profissões) e como organizadora do processo de comunicação e reprodução do conhecimento científico (proporcionando cursos de formação, editando publicações científicas, mantendo um centro de documentação, desenvolvendo actividades de cultura científica).

Os dados recolhidos pelo inquérito a associações científicas portuguesas (Figura 7) vêm confirmar que as associações científicas tenderão a constituir-se essencialmente como plataformas de comunicação e partilha de informação técnico-científica, a operar em dois registos: por um lado, o da comunicação entre pares, tendo em vista o desenvolvimento dos respectivos domínios científicos e o reforço da qualificação dos profissionais que, nos mais diversos quadros institucionais, trabalham nas áreas disciplinares cobertas por estas associações (organização de congressos, edição de publicações científicas, cursos de formação, disponibilização de informação científico- 
técnica); por outro lado, o da comunicação alargada, dirigida a públicos não especializados, tendo como objectivo a promoção da educação e da cultura científica das populações, bem como, eventualmente, a criação de melhores condições para uma mais forte visibilidade pública da ciência em Portugal e uma mais recorrente utilização dos conhecimentos de base científica no apoio aos processos de decisão individual ou colectiva (aspecto mais raramente incluído nos estatutos iniciais de muitas associações, nomeadamente de cariz disciplinar, mas que parece na actualidade alvo de atenção crescente). As associações científicas têm sido um dos tipos de participantes nas actividades promovidas pela Agência Ciência Viva, como os concursos de projectos escolares (Costa et al., 2005) ou a Ciência no Verão (Conceição, 2008; 2010).

Tal não invalida que outro tipo de actividades, pese embora mais raramente referidas como regulares, conste igualmente entre o leque de funções desempenhadas por várias das associações científicas inquiridas. Entre estas contam-se o envolvimento directo em algumas actividades de investigação científica (62\%) ou a promoção das mesmas, através da concessão de financiamentos, prémios ou bolsas (44\%), ainda que tais funções não representem, regra geral, a principal linha de actividade destas entidades, tendendo a estar a cargo de instituições especializadas - laboratórios e outras unidades de investigação, cujas actividades conheceram, aliás, forte expansão em Portugal nas últimas décadas (GPEARI, 2007; 2011).

Figura 7 Actividades desenvolvidas pelas associações científicas

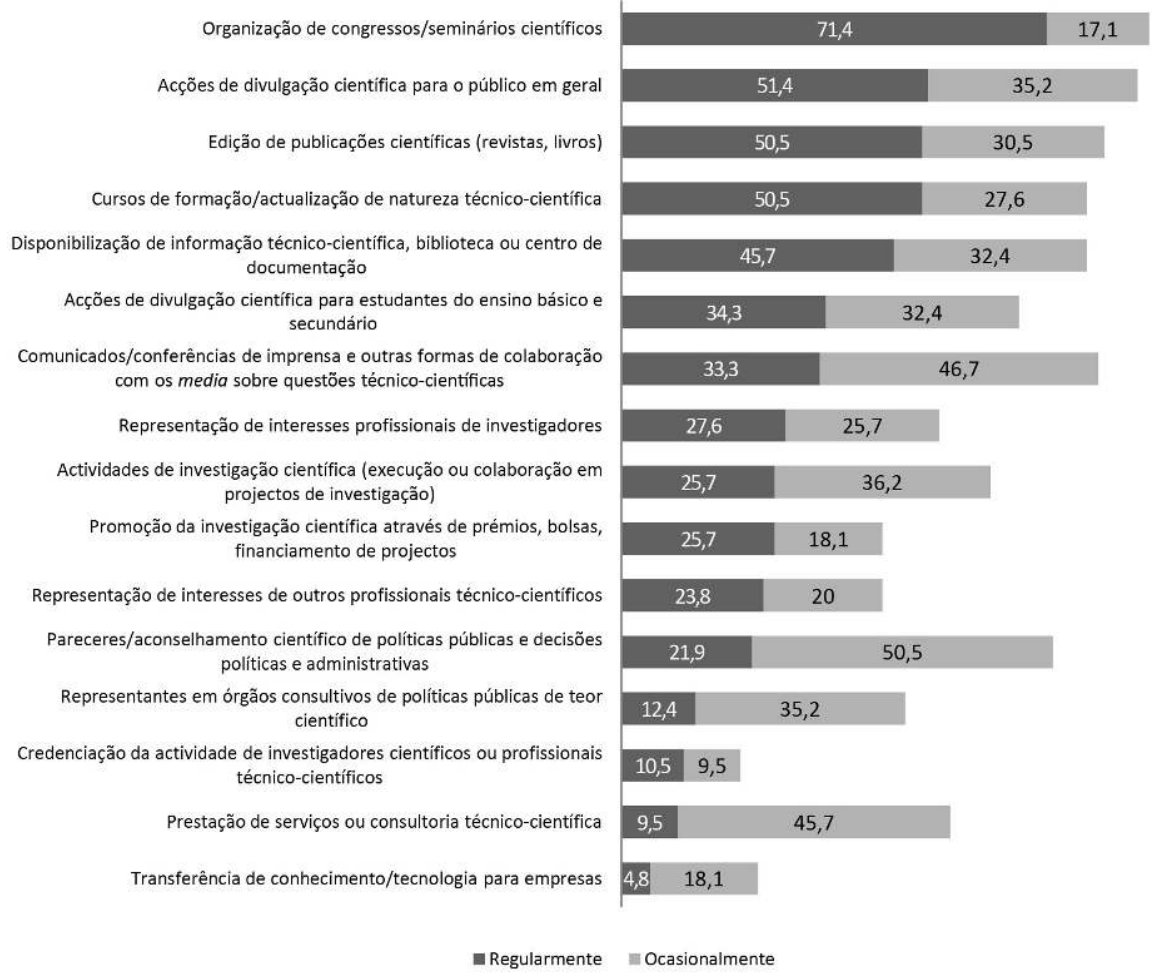

$N=105$; FONTE: Inquérito às associações científicas portuguesas (2011)

28 A representação de interesses dos profissionais ligados directamente à investigação científica tem sido, nos últimos anos, uma actividade desempenhada por ligeiramente mais de metade das associações que responderam ao inquérito (54\%). Podendo não constituir uma actividade primordial, esta parece ser, ainda assim, uma missão não 
negligenciável quando se trata de analisar o papel das associações científicas na ciência e na sociedade portuguesas. Já a representação de interesses de outros profissionais técnico-científicos tende a ser relativamente menos frequente por parte destas associações (44\%), facto que poderá estar associado à própria definição de associação científica que presidiu este estudo e que acabou por ditar a exclusão de um vasto leque de associações que se dedicam mais especificamente a este tipo de funções.

Considerando-se que as associações científicas tendem a estabelecer-se num espaço de charneira entre o campo científico, em sentido mais restrito, e outras esferas da vida social, seria certamente de averiguar em que medida a relação com as instâncias políticas (nomeadamente as encarregadas da definição de políticas públicas no campo das actividades científicas ou outras) constaria entre o leque de actividades destas associações. Os dados recolhidos através do inquérito permitem confirmar que, se é certo que muitas associações desempenham esse tipo de função, certo é também que a maioria não o fará de modo regular. Parece relativamente frequente, por parte das associações científicas, a produção de pareceres ou de documentos de aconselhamento científico tendo em vista o apoio à decisão política e à tomada de decisões administrativas (73\%). Já a assunção de funções de representação em órgãos consultivos de políticas de teor científico tenderá a ser mais escassa, embora obviamente longe de irrelevante (47\%). Efectivamente, um estudo de 1996 (Marques, 1996) dava conta de que este tipo de associações apenas estava representado em 6 conselhos ou comissões, com destaque para o Conselho Superior de Ciência e Tecnologia, o Conselho Nacional de Educação e a Comissão para a Igualdade e para os Direitos das Mulheres.

Face a estes dados poder-se-á agora questionar em que medida tal situação se deve ao facto de tais actividades serem, pela sua própria natureza, mais irregulares, ao facto de elas poderem não ser perspectivadas pelas associações como centrais no quadro da sua missão ou, ainda, a uma eventual dificuldade em aceder a estes espaços, quer esta possa advir de uma eventual fraca abertura por parte das instâncias de decisão política a este tipo de participação (cf. Gonçalves, 1996; 2001; Gonçalves e Delicado, 2009) ou do preenchimento de tais funções por parte de outro tipo de entidades a operar no campo científico (ex.: laboratórios de investigação, instituições de ensino superior, etc.). Este é um aspecto em relação ao qual se poderá vir a obter mais informação nas próximas fases do presente estudo.

Finalmente, é de referir que a prestação de serviços de consultoria técnico-científica ou outros por parte das associações científicas tende a assumir-se também como uma actividade relativamente ocasional (55\%). Bastante escassos são, por seu turno, os casos de associações que operam algum tipo de transferência de conhecimento especificamente dirigida a empresas (23\%), situação que se poderá considerar, em larga medida, consonante com o panorama durante largos anos registado no que toca às relações entre boa parte do tecido produtivo nacional e a generalidade das instituições científicas (GPEARI, 2011). A credenciação da actividade profissional de investigadores ou outros técnicos é também uma função raramente desempenhada por estas associações (23\%), visto que é uma missão praticamente circunscrita às Ordens profissionais. 


\section{Conclusões}

Os dados recolhidos permitem afirmar que as associações científicas em Portugal são um campo em forte expansão. Este tipo de organizações tem crescido a um ritmo acelerado nas últimas décadas, acompanhando o desenvolvimento do sistema científico, espalhando-se pelo território e disseminando-se em todas as áreas disciplinares.

33 As associações analisadas têm, como seria de esperar, uma forte implantação no meio científico. Têm sede em instituições de investigação ou ensino superior, agregam como associados e membros dos corpos sociais uma proporção avolumada de cientistas, desenvolvem um conjunto alargado de actividades dirigidas aos actores da comunidade científica. Há que destacar a elevada apetência das associações para a organização de encontros científicos e para a publicação de revistas científicas, o que leva a crer que este tipo de actividades continua a ter alguma importância no sistema científico português, apesar do contexto de intensa internacionalização da ciência.

No entanto, é também de destacar a sólida radicação destas organizações na sociedade. Muitas admitem como sócios não só outros profissionais científico-técnicos, como estudantes e/ou ainda outros cidadãos. Quase todas promovem a comunicação com públicos alargados através de actividades de divulgação científica, tanto para a população em idade escolar como para o público em geral. Há também um número significativo de associações que mantém alguma forma de contacto com os meios de comunicação social. É pois de admitir que as associações desempenhem um papel relevante no estabelecimento de pontes entre o meio científico e outras esferas sociais.

Outro aspecto a salientar é a relativa independência destas associações face a donativos públicos ou privados, já que a maioria das associações depende sobretudo das quotas dos associados e da prestação de bens e serviços para assegurar os seus orçamentos. Tal leva a crer que a sua actividade está sobretudo dependente de um crescimento do interesse pelo associativismo científico por parte comunidade científica em particular, mas também da sociedade em geral.

Este trabalho fica limitado pela pouca atenção que tem sido dada pela sociologia da ciência ao associativismo científico contemporâneo. A escassez de trabalhos e as características dos existentes tornam difícil realizar um trabalho de natureza comparativa, que poderia trazer uma melhor compreensão deste fenómeno, principalmente pelo enquadramento com os contextos nacionais em que concentram os principais centros de produção científica.

Outra dimensão que aqui fica por explorar é a construção de uma tipologia de associações científicas, merecedora de um artigo próprio que conjugue os resultados obtidos através do inquérito por questionário com os dados resultantes das fases seguintes de investigação, de natureza essencialmente qualitativa (estudos de caso de associações). 


\section{BIBLIOGRAFIA}

BARKE, R. P. (2003), "Politics and Interests in the Republic of Science”, Minerva, 41 (4), pp. 305-325.

BARUCH, Y, e B. Holtom (2008), "Survey response rate levels and trends in organizational research”, Humans Relations, 61 (8), pp. 1139-1160.

BIRD, S. (1998), "The role of professional societies: codes of conduct and their enforcement", Science and Engineering Ethics, 4, pp. 315-320.

BRYSON, B. (org.) (2010), Seeing further: The story of science and the Royal Society, Londres, HarperPress.

BULLOCK, M. e S. Panicker (2003), "Ethics for all: differences across scientific society codes”, Science and Engineering Ethics, 9,(2), pp. 159-70.

CAELLEIGH, A. S. (2003), "Roles for scientific societies in promoting integrity in publication ethics", Science and Engineering Ethics, 9 (2), pp. 221-41.

CARAÇA, J. (2001), o que é a ciência, Lisboa, Quimera.

CONCEIÇÃO, C. P. (2008), Ciência Viva no Verão 2008, Lisboa, Ciência Viva.

CONCEIÇÃo, C. P. (2010) Ciência Viva no Verão 2009, Lisboa, Ciência Viva.

COSTA, A. F. et al. (2005) Cultura Científica e Movimento Social - Contributos para a análise do programa Ciência Viva, Oeiras, Celta Editora.

DELICADO, A., A. N. Almeida e J. Ferrão (2002), Caracterização do voluntariado em Portugal, Lisboa, Comissão Nacional para o Ano Internacional do Voluntariado.

FREIRE, J. (org.) (2004), Associações profissionais em Portugal, Oeiras, Celta.

GIBBONS, M. et al. (1997), The New Production of Knowledge, Londres, Sage.

GOLINSKI, J. (1999), Science as public culture, Cambridge, Cambridge University Press.

GONÇALVES, M. E. (1996), "Mitos e realidades da política científica portuguesa", Revista Crítica de Ciências Sociais, 46, pp. 47-67.

GONÇALVES, M. E. (2001), “A importância de ser Europeu: ciência, política e controvérsia sobre o risco da BSE em Portugal", In J. A. Nunes e M. E. Gonçalves (eds.), Enteados de Galileu? A semiperiferia no sistema mundial de ciência, Porto, Afrontamento, pp. 171-207.

GONÇALVES, M. E. e A. Delicado (2009), “The Politics of Risk in Contemporary Portugal: Tensions in the Consolidation of Science-Policy Relations", Science and Public Policy, 36 (3), pp. 229-239.

GPEARI (2007), Investigação e Desenvolvimento em Portugal - 1982 a 2003, Lisboa, GPEARI/MCTES, http://www.gpeari.mctes.pt/archive/doc/I_Demportugal1982_2003_20092007.pdf.

GPEARI (2011), Sumários Estatísticos IPCTN 2008 - Inquérito ao Potencial Científico e Tecnológico Nacional, Lisboa: GPEARI/MCTES.

LYNCH, W. (2001), Solomon's child: method in the early Royal Society of London, Stanford, Stanford University Press.

MARQUES, M. M. L. (1996), Administração Consultiva em Portugal, Lisboa, Conselho Económico e Social. 
MATOS, A. C. (1996), "Sociedades e associações industriais oitocentistas”, Análise Social, 136-137, pp. 397-412.

MELO, D. (2011), “Associativismo e sustentabilidade no quadro local” in R. Carmo (ed.), Entre as cidades e a serra, Lisboa, Mundos Sociais, pp. 115-148.

MERTON, R. K. (1938), “Science, Technology and Society in Seventeenth-Century England”, Osiris, 4, pp. 360-632.

MOREAU, N., C. Guérot e A. Durocher (2004), “Typologie des sociétés savantes médicales françaises”, La Presse Médicale, 33 (12), pp. 784-790.

NAVE, J. G. e S. Fonseca (2000), As Organizações Não Governamentais de Ambiente, Lisboa, Observa.

RILLING, R. (1986), “The Structure of the Gesellschaft Deutscher Chemiker”, Social Studies of Science 16 (2), pp. 235-260.

RUIVO, B. (1998), As Políticas de Ciência e Tecnologia e o Sistema de Investigação, Lisboa, Imprensa Nacional-Casa da Moeda.

SCHIMANK, U. (1988), "Scientific associations in the German research system", Knowledge in Society 1 (2), pp. 69-85.

SCHOFER, E. (1999), "Science associations in the international sphere 1875-1990", in J. Boli e G. M. Thomas (eds.), Constructing World Culture, Stanford, CA, Stanford University Press, pp. 249-266.

SCHOFER, E. (2003), "International Science Associations, 1870-1990”, in G. S. Drori, J. W. Meyer, F. O. Ramirez e E. Schofer (eds.), Science in the Modern World Polity, Stanford, CA, Stanford University Press, pp. 81-99.

SCOTT, J. M., J. L. Rachlow e R. T. Lackey (2008), “The Science-Policy Interface: What is an Appropriate Role for Professional Societies?”, BioScience, 58 (9), pp. 865-869.

SHAD, J. G. (1997), "Scientific Societies and Their Journals", The Journal of Academic Librarianship, 18 (5), pp. 406-407.

SHAPIN, S. (1999), A Revolução Científica, Lisboa, Difel.

SHEEHAN, K. (2001), "E-mail Survey Response Rates: A Review”, Journal of Computer-Mediated Communication, 6 (2); [Online] Disponível em http://jcmc.indiana.edu/vol6/issue2/sheehan.html. TOMASKOVIC-DEVEY, D. et al. (1994) “Organizational Survey Nonresponse”, Administrative Science Quarterly, 39 (3), pp. 439-457.

VELTEROP, J. (2003), “Should scholarly societies embrace open access?”, Learned Publishing, 16 (3), pp. 167-169.

VESIKARI, T. (2008), "The role of scientific societies in the decision-making process to recommend new vaccines: the example of rotavirus in Europe", Journal of Public Health, 16 (4), pp. 287-290.

WEISZ, G. (2003) “The Emergence of Medical Specialization in the Nineteenth Century", Bulletin of the History of Medicine, 77 (3), pp. 536-574. 


\section{NOTAS}

1. Projecto SOCSCI Sociedades Científicas na Ciência Contemporânea, financiado pela Fundação para a Ciência e a Tecnologia (PTDC/CS-ECS/101592/2008), em curso no ICS-UL, em cooperação com o CIES-IUL e o SOCIUS-ISEG.

2. Ver também a bibliografia temática sobre associativismo voluntário compilada por D. Melo: http://www.forumlocal.org/base-de-dados/bibliografia/.

3. As fontes que constituem a base de sondagem são: a lista de Sociedades Científicas que beneficiaram do Fundo de Apoio à Comunidade Científica da FCT entre 2002 e 2006 (http:// alfa.fct.mctes.pt/estatisticas/facc/); o Roteiro de Ciência e Tecnologia (http://nautilus.fis.uc.pt/ roteiro/associacoes.htm); a base de associações profissionais do projecto de investigação do CIESISCTE "Profissões em Portugal" (http://bdapp.cies.iscte.pt/; sectores Educação e ciência, Engenharia e tecnologias, Saúde); a lista de associações que participaram em acções promovidas pela Agência Ciência Viva; portais e listagens online (Geoport, Naturlink, Psicologia.com, Universia, Sociedade de Ciências Médicas de Lisboa); website de publicações online do Ministério da Justiça (actos societários de associações); pesquisas no motor de busca Google por "associação científica" e "sociedade científica" em "site:pt"; notícias de imprensa; recomendação ou conhecimento pessoal.

4. Não é porém de excluir que algumas destas associações estejam inactivas.

5. Este valor é semelhante aos encontrados na literatura da área, que oscilam entre $30 \%$ e $40 \%$ de taxa de resposta de inquéritos a instituições, tendencialmente inferior às de inquéritos a indivíduos (Tomaskovic-Devey et al., 1994). Baruch e Holtom (2008) não encontraram diferenças substanciais entre a taxa de resposta a inquéritos por email e por correio tradicional.

6. Ainda que apenas se tenha conseguido reunir esta informação para $81 \%$ das associações científicas recenseadas (356 casos).

7. Deste pequeno grupo fazem parte a Sociedade d Ciências Médicas de Lisboa (1822), a Sociedade de Geografia de Lisboa (1875), a Sociedade Portuguesa de Ciências Agrárias (1902), a Sociedade Portuguesa de Ciências Veterinárias (1903) e a Sociedade Portuguesa de Ciências Naturais (1907).

8. Com a criação da Sociedade Portuguesas de Química e Física (1911), a Sociedade Portuguesa de Antropologia e Etnologia (1918), a Sociedade Portuguesa de Biologia (1922), a Sociedade Portuguesa de Matemática (1940), a Sociedade Geológica de Portugal (1940) e algumas Sociedades Médicas.

9. Segundo os dados do IPCTN 2008, a região de Lisboa é responsável por 56\% da despesa em I\&D, $45 \%$ dos recursos humanos em I\&D e 48\% dos investigadores (GPEARI, 2011).

10. Se bem que a divisão em núcleos ou grupos internos possa nestes casos responder à necessidade de especialização subdisciplinar.

11. Moreau et al. (2004) recensearam em França 225 associações médicas.

\section{RESUMOS}

Sendo as associações científicas um tema pouco estudado dentro da Sociologia da Ciência, este desinteresse reflecte-se num conhecimento limitado da sua extensão e do seu papel no sistema científico e tecnológico nacional.

Este artigo tem por objectivo apresentar uma caracterização destas organizações, tendo em conta a sua constituição, os seus recursos e as actividades que desenvolvem, sustentada num 
recenseamento das associações, na análise dos seus estatutos e num inquérito por questionário aplicado às mesmas.

Os resultados obtidos mostram que o número de associações científicas tem crescido a ritmo acelerado desde os anos 80 , concentrado nos principais centros de produção científica nacional. No que diz respeito à sua constituição e às actividades que desenvolvem, as associações científicas portuguesas revelam uma diversidade que nos permite caracterizá-las não só como lugares de comunicação entre pares, mas também como pontos de contacto entre a ciência e a sociedade.

Since scientific societies area a fairly under-researched subject within the sociology of science, this lack of interest is reflected on a limited knowledge of their scope and role in the national scientific system.

This paper aims to characterise these organisations in terms of their time and context of creation, resources and activities. It is based on a census of associations, an analysis of their statutes and a survey.

Our results show that the number of associations has grown steadily since the 80s and that they are concentrated in the main centres of scientific production. As to their constitution and activities, Portuguese scientific associations reveal a high degree of diversity that allows us to characterise them not just as places for fostering communication among peers but also as contact points between science and society.

\section{ÍNDICE}

Keywords: associations, science, scientists

Palavras-chave: associações, ciência, cientistas

\section{AUTORES}

\section{ANA DELICADO}

Instituto de Ciências Sociais da Universidade de Lisboa ana.delicado@ics.ul.pt

\section{LUÍS JUNQUEIRA}

Instituto de Ciências Sociais da Universidade de Lisboa

luis.junqueira@ics.ul.pt

\section{RAQUEL REGO}

SOCIUS-ISEG-UTL

raquelrego@iseg.utl.pt

\section{CRISTINA CONCEIÇÃO}

Instituto Universitário de Lisboa (ISCTE-IUL)/Centro de Investigação e Estudos de Sociologia (CIES-IUL)

cristina.conceicao@iscte.pt 


\section{INÊS PEREIRA}

Instituto Universitário de Lisboa (ISCTE-IUL)/Centro de Investigação e Estudos de Sociologia (CIES-IUL)

ines.pereira@iscte.pt 